\title{
Las artes performativas como recurso en la difusión del patrimonio arqueológico. Cómo contar la muerte de un príncipe íbero.
}

\author{
The performative arts as a resource in the dissemination of archaeological
} heritage. How to count the death of a iberian prince.

\section{Manel Jesús Torres Soria}

Universidad de Jaén, España

Instituto Universitario en Investigaciones Arqueológicas

mtsoria@ujaen.es

Recibido 23/02/2018

Aceptado 29/05/2018
Revisado 27/05/2018

Publicado 01/07/2018

\section{Resumen}

Explicar la muerte en época ibérica, tanto para adultos como para menores, ha sido un tema complejo en la animación del patrimonio. Por ello, desde la gestión del centro de Interpretación de las Tumbas Principescas de Toya y Hornos (Peal de Becerro, Jaén), se estableció otra forma de acercar al público un tema tan complejo como la muerte de los iberos, creando como elemento vehicular la visita teatralizada.

\section{Abstract}

Explain the death in Iberian times, both for adults and childrens, has always been a complex issue in heritage animation. For this reason, from the management of the Interpretation Center of tumbas principescas de Toya and Hornos (Peal de Becerro, Jaén), another way of bringing to the public a topic as complex as the death of the lberians was established, creating as a vehicular element the Theatrical visit.

Para citar este artículo

Torres Soria, Manuel (2018). Las artes perfomativas como recurso en la difusión del patrimonio arqueológico. Cómo contar la muerte de un príncipe íbero. Tercio Creciente, 14, págs. 145-154. https://dx.doi.org/10.17561/rtc.n14.12 
ISSN: 2340-9096

DOI: https://dx.doi.org/10.17561/rtc.n14.12 www.terciocreciente.com

Investigación

Palabras clave / Keywords

Investigación artística, Animación turística, visita teatralizada, Toya, Peal de Becerro, príncipe íbero, muerte.

Artistic research, Theatrical visit, Toya, Peal de Becerro, Iberian prince, death.

Para citar este artículo

Torres Soria, Manuel (2018). Las artes perfomativas como recurso en la difusión del patrimonio arqueológico. Cómo contar la muerte de un príncipe íbero. Tercio Creciente, 14, págs. 145-154. https://dx.doi.org/10.17561/rtc.n14.12 


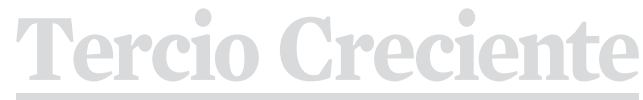

ISSN: 2340-9096

DOI: https://dx.doi.org/10.17561/rtc.n14.12

\section{Introducción. Otra forma de ver la animación del patrimonio.}

La definición de animación del patrimonio no permanece aún en nuestro ideario de una forma clara y concisa. Siempre suele diluirse en una serie de actividades relacionadas con conocer el patrimonio, sin aportar algo diferente, cuya "animación" sea solo más actividad dentro del turismo patrimonial de la zona. Como indica J.Morales: "la terminología de interpretación del patrimonio esta bien definida desde el último tercio del siglo XX pero en España no se aplica correctamente." (Morales, 1999: 150). Y en consonancia con la anterior apreciación, la animación del patrimonio va en la misma línea, es un concepto muy usado pero vacío de contenido en su aplicación.

Por ello, la discusión acerca de la terminología a usar, sobre todo en el aspecto de marketing y de oferta al público, refleja un uso inadecuado de la misma. Visita guiadas, visitas lúdicas, visitas teatralizadas, visitas animadas, etc., todo ello buscando en la afinación al máximo de la actividad para ofrecer una mayor calidad en la animación. Pero ante ello, se observa que cuando se usan algunas referencias a actividades fuera de "lo establecido" con el objeto de definir correctamente dicha actividad, el público se siente confundido con la misma y no accede de la misma forma a la animación, llevando a multitud de actividades al fracaso.

Por este motivo, toda la animación del patrimonio debe entenderse como el medio interpretativo de participación del público en el descubrimiento de la historia, cultura y valores ambientales de un lugar determinado a través de animadores/intérpretes caracterizados (Benítez, 2007: 3). Y en el caso que nos ocupa, la visita teatralizada será la acción más representativa de animación. Concebida ésta como una escena con personajes relacionados en el ámbito cultural donde se realiza y que éste sirve como escenario de la misma. Sólo que el público debe formar parte del acto, ofreciendo nuevas líneas de argumentación así como desenlaces diferentes. Atendiendo a la última frase, tendríamos que definirla con más exactitud con el concepto de visitas animadas por la acción determinante con el público. Sin embargo, y volviendo a la posible confusión del público respecto a la denominación de la actividad, proponemos la denominación de visita teatralizada como más definitoria e identificativa de nuestra forma de ver el acercamiento a la historia y al patrimonio. Parafraseando a V. Gessman, el teatro no se hace para contar las cosas, sino para cambiarlas.

2. El contexto: centro de interpretación de las tumbas principescas de Toya y Hornos (Peal de Becerro).

En el centro histórico de Peal de Becerro (Jaén) se puede visitar el Centro de Interpretación de las Tumbas Principescas de Toya y Hornos, donde se introduce al mundo de la muerte y los ritos funerarios en época ibérica. Un edificio construido en 2013 y financiado por la Diputación Provincial de Jaén dentro del programa turístico de Viaje al Tiempo de los Iberos. Dicho edificio forma parte de un conjunto de infraestructuras, contando con un Aula didáctica así como el propio espacio arqueológico, que hacen que sea un espacio único en la provincia. Para el caso que nos ocupa, nos centraremos especialmente en el Aula didáctica, sito en la ladera donde se encuentra el yacimiento arqueológico, y en la propia cámara funeraria de Toya. 
La Cámara de Toya se localiza a unos 5 kilómetros en dirección a la aldea de Hornos. La estructura arquitectónica de la cámara tiene una planta cuadrangular y su interior se divide en tres naves longitudinales, la central tiene la única puerta de acceso a la construcción. Las dos naves laterales, a diferencia de la central, están divididas en dos espacios cada una de ellas; el primero, a modo de antecámara, comunica en ambos casos con la nave central. Los sillares de la construcción, perfectamente labrados, se colocaron sin ayuda de grapas o mortero, es decir, van montados en seco. La cubierta se caracteriza por una serie de grandes losas que se apoyan en los muros de las estancias longitudinales (Cabré, 1925: 78).

El producto turístico del Viaje al Tiempo de los Iberos es consecuencia de un patrimonio acumulado de extraordinaria importancia en calidad y en cantidad, cuyo tratamiento, posterior a la pura intervención arqueológica, ha sido desafortunado, a excepciones contadas como la Cámara de Toya y Cástulo. El resto de asentamientos, las medidas de conservación, de simple protección o de mera vigilancia han sido inexistentes. Por no decir de la difusión y puesta en valor de ese patrimonio hasta la creación de dicho producto turístico (Ruiz et alii, 2015: 487).

Viaje al Tiempo de los Iberos ha creado un viaje base en el que se incluye la visita a los centros de interpretación y salas ibéricas en museos locales como el Museo Monográfico de Cástulo en Linares y los Museos Locales de Porcuna y de Castellar o el Museo Ibero. Además de musealizaciones al abierto de lugares como la Plaza de Armas de Puente Tablas, la cámara sepulcral de Toya, Cerrillo Blanco, Cástulo, los santuarios rupestres de la Cueva de la Lobera y de Despeñaperros, hitos fundamentales para comprender la historia de los iberos (Ruiz et alii, 2015: 493).

Como venimos tratando, una de las paradas en este viaje temático, es la Cámara de Toya (Peal de Becerro). El objetivo de esta visita es mostrar cómo es una cámara funeraria principesca y su significado en el contexto de la sociedad aristocrática ibérica. Para ello, se pretende desarrollar un contenido histórico cuyo motor pivote sobre dos aspectos clave de la sociedad ibera: la figura del príncipe como elemento aristocrático aglutinador de la sociedad de Tugia, en este caso; y por otro lado, construir un ideario de la vivencia del más allá en las iberas e iberos del siglo IV a.n.e. (Ruiz et alii, 2015: 494).

Sin duda, la importancia de este viaje temático y producto turístico viene dada por las actividades de carácter difusor y lúdico que acompañan a cada uno de los centros de interpretación y yacimientos arqueológicos que componen Viaje al Tiempo de los iberos. Actividades muy relacionadas, en gran parte, con la animación del patrimonio mediante visitas teatralizadas, talleres temáticos o visitas especializadas. Todo ello a crear un dinamismo generador por un lado de riqueza.

\section{La gestión de las tumbas principescas.}

En el año 2016, la empresa Turistoria, Gestión y Difusión del Patrimonio se hace cargo mediante contrato público con el ayuntamiento de Peal de Becerro (Jaén) de las Tumbas Principescas de Toya y Hornos. El objetivo del contrato no era otro que llevar a cabo la gestión integral del centro de interpretación por parte del sector privado. Para ello, la empresa adjudicataria genera un proyecto de servicio por dos años en el cuál se intenta ubicar al espacio del Centro de Interpretación como el centro de actividades culturales y turísticas de Peal de Becerro.

El proyecto pivota sobre dos ideas muy claras por parte de los gestores. La primera de ellas, es ofrecer una visita guiada por especialista en arqueología tanto al centro de interpretación como al propio yacimiento. Con ello, se pretende dar un salto de calidad a las mismas ofreciendo una visión diferente al visitante. La figura del arqueólogo invita al cliente a establecer un vínculo de confianza profesional, además de una cierta empatía, ya que la arqueología es una profesión muy apreciada por 


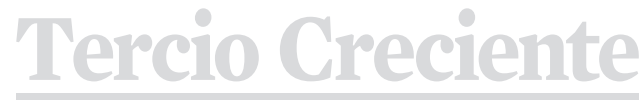

ISSN: 2340-9096

DOI: https://dx.doi.org/10.17561/rtc.n14.12 una parte de la sociedad, a la vez que muy denostada por la otra parte. La visita completa, de una hora y media de duración, introduce al visitante al mundo ibero a través del patrimonio funerario con dos tumbas únicas en la Península Ibérica. Se conoce la vida de la sociedad ibera a través de la muerte, puesto que gran parte de la riqueza patrimonial proviene de las excavaciones de espacios funerarios iberos. Sin embargo, explicar la complejidad de la sociedad ibera a través de dos tumbas se hace harto complicado puesto que se desconoce a los iberos y a las iberas casi por completo (nos hemos encontrado con una gran cantidad de visitantes que no conocían la existencia de este periodo histórico); y más aún, utilizando como medio explicativo el ritual funerario, el ajuar, el contexto físico, la ubicación de la tumba, etc. Pero todo se complica aún más cuando las visitas son escolares, donde el tema de la muerte está muy difuminado y con grandes dosis de tabú (se establecen actividades de tipo talleres dirigidas al público infantil para paliar este problema).

Y la segunda base sobre la que se sustentaba el proyecto de gestión cultural está íntimamente relacionado con las últimas ideas del párrafo anterior: hacer comprensible la temática del centro de una forma creativa con actividades que lo favorezcan. Por ello, se crean dos actividades que hasta día de hoy han sido un éxito no sólo de público sino de consecución de objetivos. La noche de los candiles, una de las actividades, está enmarcada en la noche del 31 de octubre y se puede describir como una visita tanto al centro de interpretación como a la Cámara Sepulcral de Toya con el único apoyo lumínico de antorchas, velas y candiles. La calle de acceso al centro de interpretación se ilumina únicamente con un pasillo marcado por velas que indica el acceso al mismo. Dentro del centro de interpretación, la luz vuelve a ser un camino de velas estableciendo el recorrido de la visita; mientras que los candiles iluminan el espacio donde se encuentra la reproducción a escala 1:1 de la Cámara de Hornos. La única salvedad en el uso de electricidad es en la reproducción del video introductorio al visitante (hecho necesario para toda la visita). En cuanto a la visita al propio yacimiento, éste se hace desde el pueblo con un tren turístico. Una vez, en el yacimiento, se usan las antorchas para iluminar el espacio colindante a la tumba principesca y el interior de la misma, con candiles. Asimismo, el interior de la Cámara de Toya se decora con las reproducciones de los elementos encontrados durante las intervenciones arqueológicas.

Esta visita tiene una serie de características que la hacen muy atractiva:

a) Contexto: el hecho de ubicarla en la noche previa de los santos tiene el objeto de crear un "ambiente mágico" para el visitante. Tener la sensación del viaje al inframundo, al igual que podían tener los iberos del siglo IV a.n.e.

b) Sostenibilidad: el uso de una iluminación no eléctrica ofrece al visitante una oportunidad única de concienciarse de la dependencia de la sociedad actual con la electricidad.

c) Exclusividad: es una visita que se realiza una vez al año, lo que la convierte en un atractivo muy exclusivo y único

\section{Enterrando a un príncipe}

Es La otra actividad es el entierro del príncipe de Tugia, una visita teatralizada o dramatizada, en la cual el visitante es el motor de la misma, pudiendo modificar el transcurso de ella. En la visita, se reproduce el ritual de enterramiento de un príncipe ibero del siglo IV a.n.e. mediante tres actores con roles muy bien marcados e identificativos de la sociedad ibera. Estos actores forman parte del Grupo de Recreación Histórica de Úbeda, grupo que tiene como claro denominador la formación exhaustiva de sus integrantes en la historia, arqueología y arte de cada una de las etapas históricas que representan; y que ofrecen una acción didáctica en cada una de las visitas teatralizadas.

La actividad se desarrolla en tres escenarios 


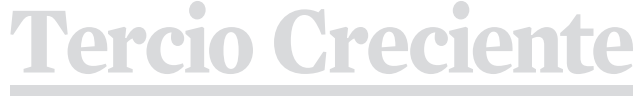

ISSN: 2340-9096

DOI: https://dx.doi.org/10.17561/rtc.n14.12
Revista de Estudios en Sociedad,

Artes y Gestión Cultural

www.terciocrecientecom

http://revistaselectronicas.ujaen.es/index.php/RTC distintos: por un lado, en el Aula Didáctica, se lleva a cabo la acción de ofrecer el respeto a la familia del difunto príncipe, así como renovar el contrato social que los vincula a su familia. Recibido el visitante por un viajero griego, que será quién guie toda la visita, explicando cada uno de los pasos que forman la actividad, y cuya objetividad en cuanto a la visión de la sociedad ibera ayuda al visitante en su compresión de lo que sucede. Él es quien organiza las familias que tienen que presentarse ante el príncipe heredero, creando varios grupos que deben obtener todo el atrezzo necesario para realizar bien su acción. Una vez constituidas las familias, se procede al interior del edificio, donde se encuentra el difunto en el centro del mismo, vigilado en la cabecera por el heredero y la viuda. Es el momento de entregar los bienes que sirven de homenaje al difunto y del acto de renovación de la relación clientelar mediante un discurso por parte del representante de cada una de las familias.

Una vez finalizada esta primera parte, se organiza un cortejo que trasladará al difunto desde su lugar de velación hacia su lugar de descanso eterno. Este desfile que organiza el viajero griego cuenta con diferentes aspectos: plañideras junto al difunto, músicos abriendo la procesión, cantantes entonando himnos fúnebres, portadores de las ofrendas, etc. Como se habrá podido observar, este punto de la visita es donde más licencias nos tomamos a la hora de la historia. Intentamos acercarnos a la misma a través de las cerámicas y descripciones encontradas, pero si somos ortodoxos en la misma, podríamos caer en la tentación de hacer recreación más que dramatización o teatralización, más enfocada al ocio.

El tercer espacio escénico es la propia Cámara de Toya, lugar de reposo de los restos del difunto. Tras el cortejo fúnebre, en la explanada del yacimiento arqueológico, se lleva a cabo una simulación de cremación (muy controlada y para nada fiel a la posible realidad, por criterios más que evidentes) y unos combates rituales honoríficos, donde algunos de los visitantes pelean entre sí por el honor del príncipe difunto. Tras éstos, el guía ofrece una explicación sobre la Cámara de Toya, que a continuación, es visitada en grupos por todos los visitantes. En el interior de la misma, se encuentra la viuda del difunto velando por los restos de su esposo que han sido depositados allí, así como todo el ajuar generado durante la visita.

Los actores representan los siguientes papeles:

a) Hijo del difunto: o el heredero de la ciudad de Tugia. Vestido con túnica corta, debido a la juventud del mismo, manto con broche al hombro y cinturón con cierre de fíbula, al que se le añade como arma, una falcata. Su función es establecer la continuidad de la familia en el poder, siendo él, el máximo garante de esa dinastía. Es quién recibe las ofrendas y ofrece la renovación del contrato de la familia con su clientela (la sociedad ibera supera los límites organizativos sociales del vínculo de sangre y establece relaciones de don-contradon con gran parte de la sociedad), que en muchos casos, negocia el mismo para crear un nuevo marco de la relación clientelar. Muestra una actitud orgullosa y distante respecto a los personajes que vienen a ofrecerle sus dádivas a la familia.

b) Viuda: y madre del heredero. Con una túnica larga de lino acompañada de un sobre manto de color y un velo que cubre en parte su rostro, y que proviene de una mitra situada en su cabeza. Ornamentada con un collar y varios brazaletes, tiene que ostentar en su vestimenta todo el lujo de la familia, mostrando así su poder y estatus social. Su actitud es diferente al anterior personaje, apenas interviene sólo cuando la situación que se presenta, es un claro peligro para la familia. Su papel es puramente ostentoso, aun así, en la sociedad ibera, la legitimidad de una familia siempre era portada por la mujer, pero en los ritos sociales, la mujer ofrece una actuación secundaria.

c) Viajero griego: es el hilo conductor de toda la actividad, pues es quien ofrece al visitante todas 


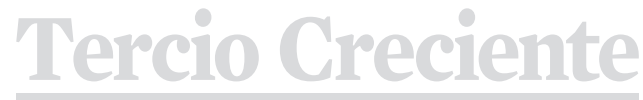

ISSN: 2340-9096

DOI: https://dx.doi.org/10.17561/rtc.n14.12 las claves para entender y/o participar en la visita. Su intermediación viene dada por su profundo conocimiento de la sociedad ibera pero sobre todo, por su aspecto imparcial de la misma. Introduce a las familias de la ciudad de Tugia para seguir con el rito de presentación de respeto por el difunto ante la familia, así como, dirige las diferentes actividades funerarias que componen el rito funerario.

d) Familias: interpretadas por los visitantes, que son organizados por el viajero griego en las diferentes familias que componen la sociedad (artesanos, ganaderos o agricultores) y que deben ofrecer sus presentes a la familia del difunto $y$ renovar su relación con ellos. Es el actor más dinámico y condicionante de la actividad, su actitud participativa así como su imaginación en los distintos parlamentos ante la familia, guían las pautas de los anteriores papeles descritos.

\section{Cocluyendo}

La arqueología, o mejor dicho las arqueólogas y arqueólogos, hemos comprobado que nuestro papel en la sociedad no es sólo documentar y conservar el patrimonio, sino que hay que difundirlo: difusión como parte esencial y determinante de nuestro trabajo para conseguir nuestros objetivos para con nuestro patrimonio. De tal forma, que debemos ser capaces de dar los datos recabados de forma abierta y fácil de entender para la sociedad con el objeto de originar un contexto histórico bien delimitado. Si a todo ello sumamos, lo dificultoso y poco atractivo que resulta la visita a un yacimiento arqueológico sin más apoyo que unos panfletos o las explicaciones de un guía, conducen a un callejón sin salida para la consecución de objetivos claros. Datos en bruto para que los gestores culturales puedan generar actividades y acciones que favorezca una difusión sostenible del patrimonio.

Y para ello se debe hacer desde la más absoluta ortodoxia respecto a la historia y contando con todos los elementos que nos acerquen a ella. Es aquí donde entra en juego la animación del patrimonio como herramienta necesaria para establecer un primer acercamiento al patrimonio. Un acercamiento basado principalmente en la propia experiencia para concienciar al visitante de la pertenencia del sitio visitado y establecer un vinculo más profundo que la visita guiada o simplemente la visita al lugar arqueológico.

Como explicamos al principio del artículo, el concepto de animación del patrimonio no tiene claridad de definición, lo que dificulta su aplicación al mismo de una manera específica y lo peor de todo, es que genera, por las diferentes denominaciones, confusión en el visitante. Se hace más que evidente una reflexión profunda de dicho concepto por parte de todos los actores que intervienen en la difusión del patrimonio.

Contando con el amplísimo abanico de acciones para con el patrimonio, la visita teatralizada o dramatizada con una actuación dinámica por parte de las y los visitantes es el ejemplo más preciso de animación del patrimonio. Volvemos a repetir si ésta se hace desde la ortodoxia y el respeto por la historia, se convierte en un vehículo potente para crear conciencia y sentimiento de pertenencia del visitante con el patrimonio. El objetico último es ese: concienciar desde el arte, en este caso, desde la teatralización. 
Tercio Creciente

ISSN: 2340-9096

DOI: https://dx.doi.org/10.17561/rtc.n14.12
Revista de Estudios en Sociedad, Artes y Gestión Cultural

www.terciocreciente.com

http://revistaselectronicas.ujaen.es/index.php/RTC
Número 14

Julio 2018

Investigación

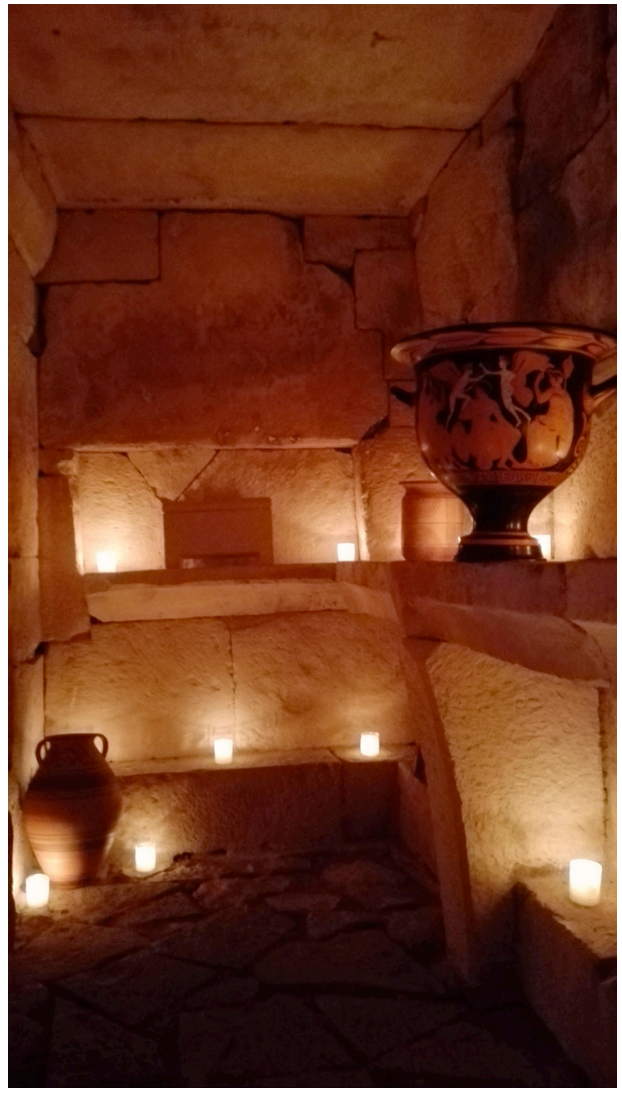

Fig. 1. Interior de la Cámara de Toya en la Noche de los candiles.

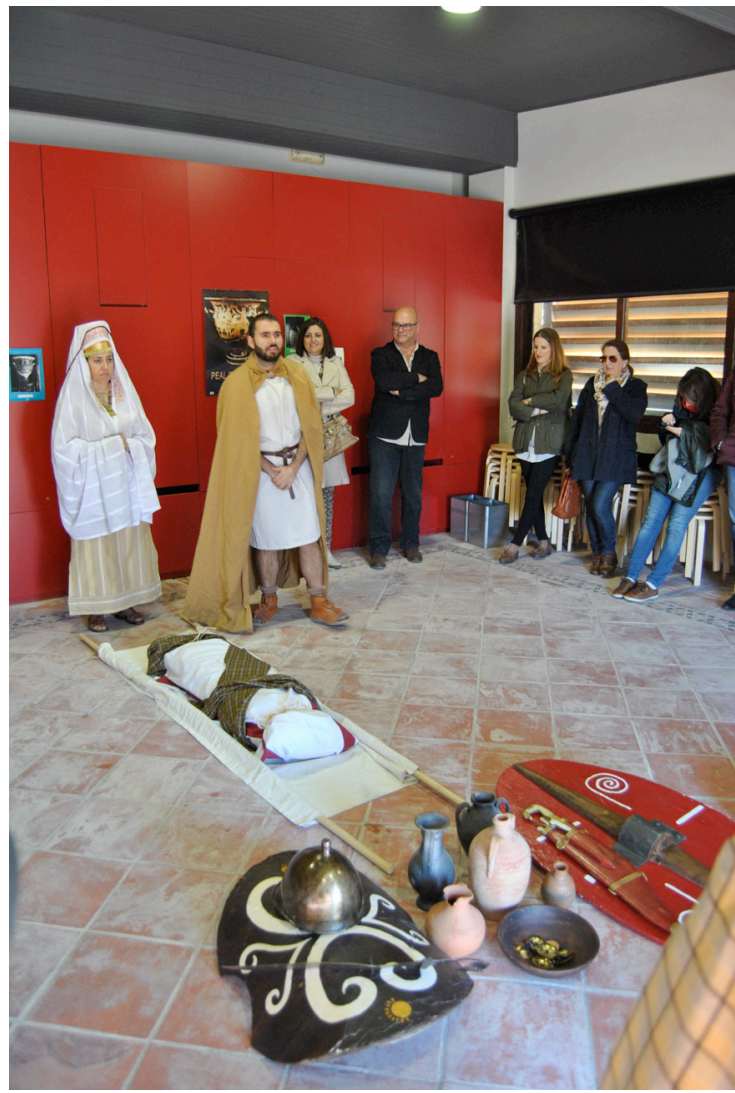

Fig. 3. Visita teatralizada. Momento de la presentación de respeto por parte de los visitantes.

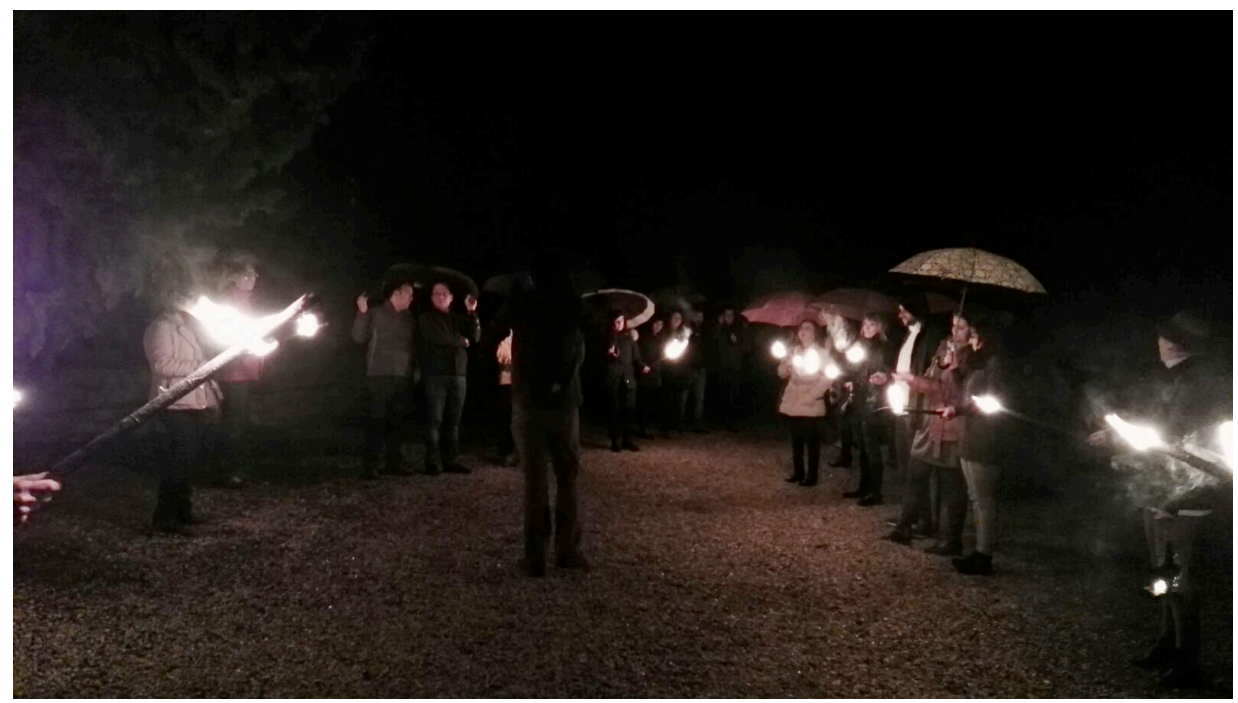


Tercio Creciente

ISSN: 2340-9096

DOI: https://dx.doi.org/10.17561/rtc.n14.12
Revista de Estudios en Sociedad, Artes y Gestión Cultural

www.terciocreciente.com

http://revistaselectronicas.ujaen.es/index.php/RTC
Número 14

Julio 2018

Investigación

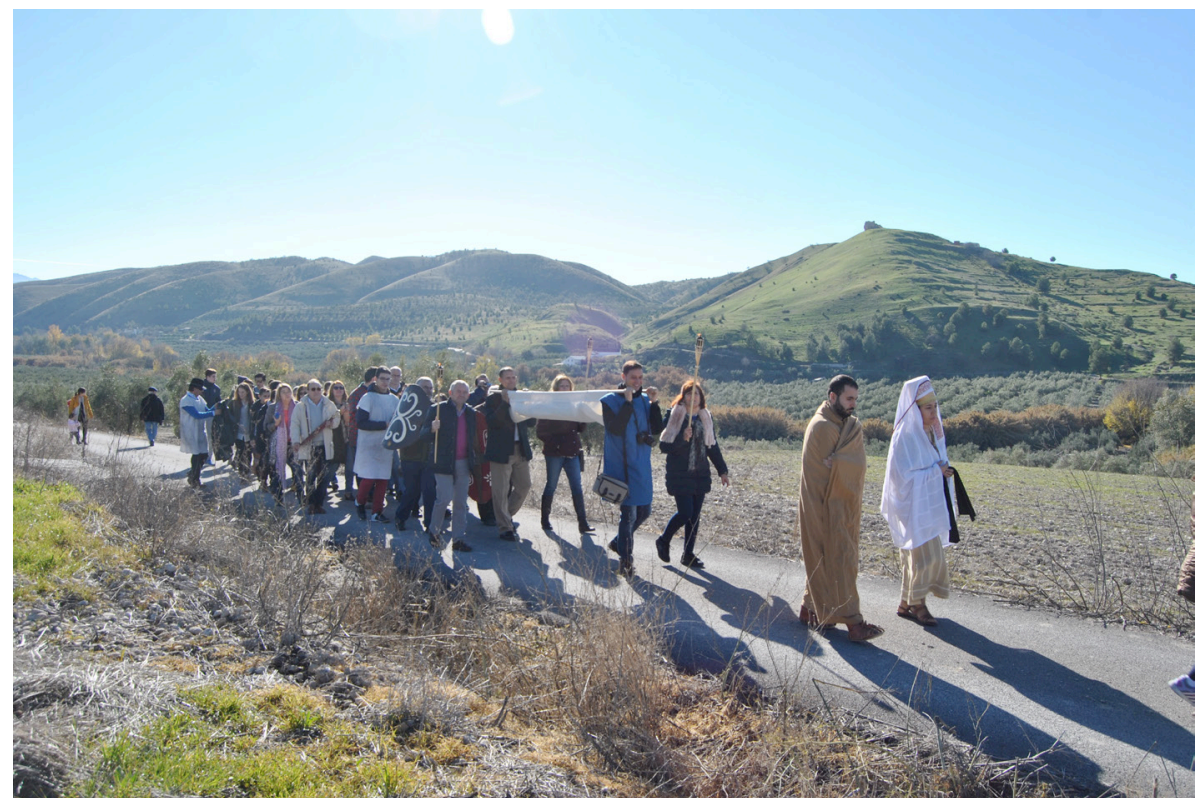

Fig. 4. Visita teatralizada. Cortejo fúnebre.

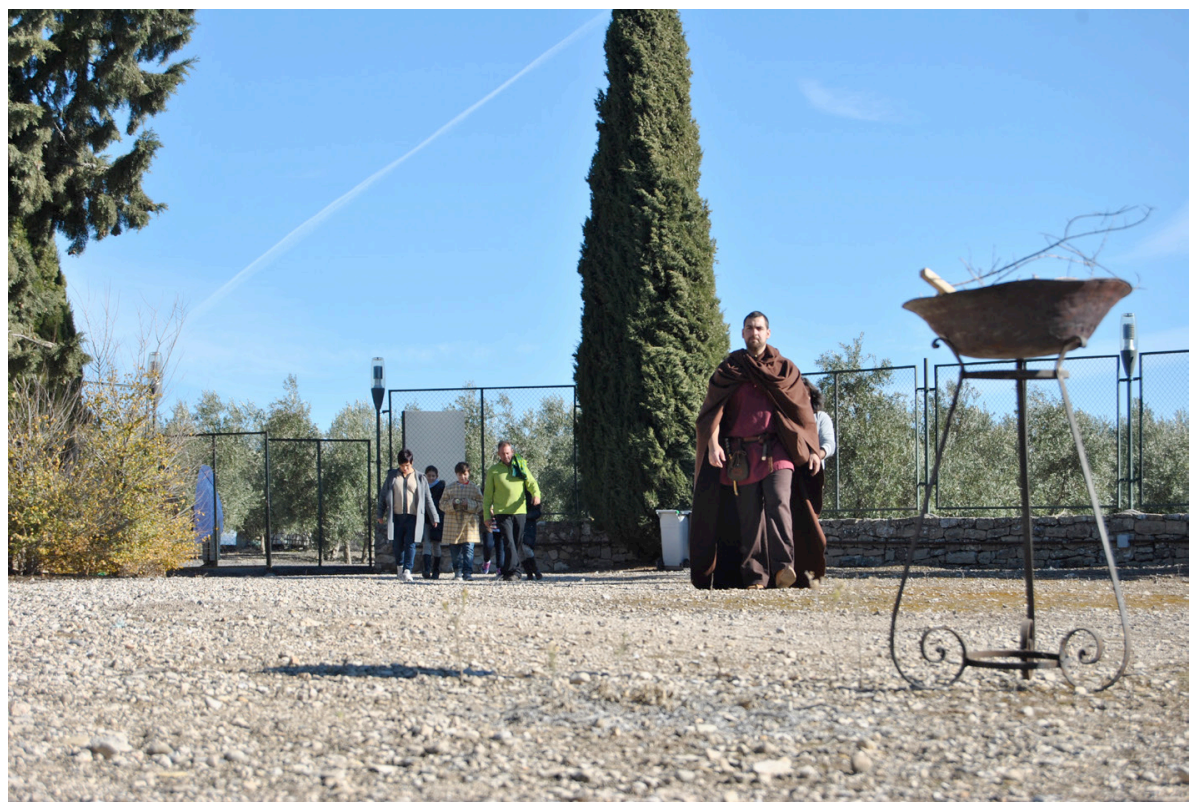

Fig. 5. Visita teatralizada. Llegada del cortejo fúnebre y comienzo de los combates rituales. 


\section{Referencias}

Benítez Muñoz, F.J. (2007): Reflexiones en torno a la animación del patrimonio. En Boletín de Interpretación, 17 (pp. 3-4). A Coruña: Asociación para la interpretación del Patrimonio.

Cabré Aguiló, J. (1925): Arquitectura Hispánica: El Sepulcro de Toya. En Archivo Español de Arte y Arqueología, n० 1 (pp.73-102). Madrid: Centro de estudios históricos. Junta para ampliación de estudios e investigaciones científicas.

Morales Miranda, J. (1999): La interpretación del patrimonio natural y cultural: todo un camino por recorrer. En PH Boletín, 25 (pp. 150-157). Sevilla: Instituto Andaluz del Patrimonio Histórico de la Junta de Andalucía.

Ruiz, A.; Molinos, M.; Fernández, A. y Barba, V. (2015): Viaje al tiempo de los iberos. En Ruiz, A. y Molinos, M. (coord.) Jaén, tierra ibera. 40 años de investigación y transferencia (pp. 487-502). Jaén: Universidad de Jaén. 